\title{
Browsing impacts on Acacia drepanolobium Sjøstedt and associated ant guilds in Ol Pejeta Conservancy, Kenya.
}

\author{
Noel O. Olweny ${ }^{\mathrm{a}, \mathrm{d}, *}$, Geoffrey M. Wahungu ${ }^{\mathrm{c}, \mathrm{d}}$, Gilbert O. O. Obwoyere ${ }^{\mathrm{b}, *}$ \\ anoelotolweny@gmail.com \\ *Department of Natural Resources, Egerton University P.O Box 536-20115 Egerton, Kenya \\ ${ }^{b}$ Dean Faculty of Environment and Resources Development, Egerton University, Njoro, Kenya \\ ${ }^{\mathrm{c}}$ School of Natural Resources \& Environmental Studies, Karatina University College, P.O Box 1957, 10101 Karatina, Kenya \\ ${ }^{\mathrm{d}}$ Earthwatch Institute, Kenya's Black Rhino Project, Ol Pejeta Conservancy, Private Bag, Nanyuki, Kenya
}

\begin{abstract}
The numbers of Acacia drepanolobium trees are declining over much of Africa and large mammals particularly more prone and vulnerable to loss of habitat owing to human settlement encroachment. In Ol pejeta conservancy a sanctuary for the protection of the endangered black rhino, there is significant browse and vegetation pressure on the habitat particularly on the Acacia drepanolobium tree population. This study aimed to investigate the Acacia drepanolobium and ants' interaction under different browsing intensities, determine effect of prescribed burnings on Crematogaster ants and Acacia drepanolobium interaction, investigate the tenancy dynamics of ants under varying morphological characteristics of Acacia drepanolobium trees, and finally to determine if Crematogaster ants' communities/ colonization on Acacia drepanolobium change over time. Twelve (12) randomly chosen plots (keyed in a waypoint on the GPS) with fifty or more Acacia drepanolobium trees were studied for the study as follows, two (2) in a Chimpanzee Sanctuary where elephant, giraffe and rhino are excluded (control), six (6) in the reserve and four (4) in the Ranch. Two (2) plots treated with prescribed burning (fire) were compared with two un-burnt plots. All data collected was fed and entered into Excel spreadsheet and Statistical Package for the Social Science version 20 for analysis. The data were then processed into quantitative tables to give a comparative analysis for response obtained. Size class distributions of the reserve, Ranch and control were compared by means of Analysis of Variance (ANOVA) and other relevant parametric statistics. The result shows that in $\mathrm{Ol}$ pejeta conservancy browsing levels has statistically significant effect on Crematogaster ants and Acacia drepanolobium interaction. There was a strong and notable distinction between the four acacia ant species in the overall extends and levels of tenancy while responding to varied browsing pressures; Crematogaster mimosae and Tetraponera penzigi were found to be the most abundant/frequently observed ant species occupying trees in the reserve where there is intensive browsing (Reserve) and the ranch with medium browsing intensity. From this research experimental evidence explains the ability of trees to re-induce greater spine and gall numbers and that ant tenancy in A. drepanolobium is influenced by the tree's morphological characteristics. The findings and results also indicated that prescribed burning significantly affected the type of ant inhabiting the A. drepanolobium tree. Going by the results of this paper, it was concluded that this mutualism is a key component of $\mathrm{Ol}$ pejeta biodiversity and ecosystem function. The study recommends that the results in this research should be used in determining ecological factors that influence conservation sustainability and predict the consequences of heavy browsing pressure, morphological characteristics and prescribed burning on the health of Acacia drepanolobium.
\end{abstract}

Keywords: Acacia drepanolobium, Browsing, Crematogaster Ants, Guilds, Galls, Spines

\section{Introduction and Background of the Problem}

Scientific studies and a growing amount of research have prioritized African swollen thorn acacias as the subject with increasing speculation regarding relationships and links with their traditional ant inhabitants (Burtt 1942; Brown 1960; Monod and Schmitt 1968; Hocking 1970; Coe and Beentje 1992; Madden and Young 1992; Davidson and McKey 1993a, b). Hocking (1970) gave a detailed description of the rich and inevitable invertebrate fauna linked with this symbiosis, and observed that a number of ant species displayed mutual exclusivity, without giving quantitative analysis and description of variations among the ant occupants. Many herbivores have the habit and tendency to discriminatively browse most acacia trees than other tree species since they tend to be nutritious (Fornara \& du Toit, 2007). This carries a risk of lowering 
recruitment and reproduction (Young \& Augustine, 2009). Physical and chemical defences are then developed in response and this may entail reactions such as growth response. Variations in plant phenology ad massive compensation are some of the growth responses deployed to minimize the impacts of the resulting herbivory. The mechanical and physical mechanisms of defense aim at minimizing the general accessibility of the plant leaves by increasing the densities and length of the spine and consequently reduce the size of the leaves. The prickles/thorns and thorns are responsible for defending the acacia plants and trees from persistent attcks from consistent and regular browsing pressure of elephant, gerenuk, impala, and giraffe (Dharani, 2006).

In East Africa the most common swollen thorn acacias include Acacia gerrardii, Acacia seyal and Acacia drepanolobium. The protection mutualisms that exist between ants and plants have acted as testing tractable systems that test the aspect of the defense theory of plants (Fonseca 1994, Heil et al. 2001). Myrmecophyte symbioses, for a long time, have acted as excellent models with reliable frequency for conditional outcome examination of interactions between species (Gaume et al., 1999) and the comprehensive understanding of the stability that exists in evolutionary theory and stability of mutualisms despite the conflicts that carry destabilizing conflicts (Yu 2001). Acacia drepanolobium establishes a symbiotic relationship by growing swollen galls that contain active and aggressive ants Crematigaster nigriceps and Crematigaster mimosa colonies and settlements (Dino, 2010). The symbiotic ants act to deter and prevent deter browsing by large herbivores that use their muzzles to irritate and attack during the browsing process.

Acacia drepanolobium is a single stemmed most occurring and dominant type and species of tree thriving in most of East Africa's black cotton soil and can reach heights of up to 7m (Coe \& Beentje, 1991). Acacia species, that even includes A. drepanolobium, tend to naturally suffer significant herbivory many herbivores prefer them for food like: black rhinos (Diceros bicornis), elephants (Loxodonta Africana), and giraffes (Giraffa Camelopardalis), which contain trip divisions on either side on their young shoots and leaves (Pellew 1983; Milewski et al. 1991; Young and Isbell 1991, Wahungu et al, 2012). A. drepanolobium is unusual in that it produces swollen structures at the base of paired spines called galls. Galls can reach up to $5 \mathrm{~cm}$ and are usually occupied by symbiotic resident ants which feed from nectarines produced by the tree at leaf bases (Madden \& Young 1992; Young et al. 1997). Species of Crematogaster are symbiotically hosted by A. drepanolobium and Tetraponera ants. Crematogaster ants which have been widely studied include $C$. mimosa, C. nigriceps and C. sjostedti while Tetraponera penzigi has also gained research interest as a symbiotic species. A. drepanolobium ant symbiotic relationship has been the subject of several research studies (Hocking, 1970; Stanton et al., 1999; Young et al., 1997). These symbiotic ants beef-up tree protection by acting as a nuisance towards the browsers. Once a tree is disturbed by a browser, the ants secrete a noxious and potent warning pheromone which can trigger ants similar or varying species inhabiting adjacent trees to show the alarm behaviour and habit (Wood \& Chong, 1975). Each species secretes both complex and distinct pheromone in terms of chemical.

There is a lot of browse and vegetation damage pressure on the habitat particularly on the Acacia drepanolobium at Olpejeta conservancy. The symbiotic ants protect their host acacia tree against broad range of these herbivores. Heil and McKey (2003) indicated that plants that lack ants tend to suffer elevated and exaggerated extends of herbivory as compared to conspecifics that have ants but instead, the decline of the Acacia drepanolobium trees is on the rise at Olpejeta conservancy threatening the lives of the mega herbivores which uses the tree as food. Therefore, factors which affect the ability of the symbiotic ants to protect the tree are to be doubted; intense browsing pressure has been shown to cause poor tree growth, low reproduction or even death (Wahungu et al., 2010) Morphological characteristics of the tree (numbers of spines and galls) which are also meant to protects the tree from the browsers can also be attributed to affect the mutual relationship which results to the decrease in Acacia drepanolobium tree's health and population. If the decline continues, the population of the mega herbivores and the long term conservation of the black rhino will be threatened having sobering implications for conservation (See also Wahungu et al., 2011). Therefore, study is valuable for the sustained management of large browsers and their foliage, especially under the intense conditions suffered within sanctuaries. The understanding of factors that affect variability in Acacia 
drepanolobium and symbiotic ants' guilds following varied browsing intensities also help determine ecological factors that will influence conservation sustainability thus aid in habitat management and help predict the consequences due to change of habitat.

In this study, we checked on the variability in Acacia drepanolobium_and symbiotic ants' guilds following varied browsing intensities at Olpejeta for over the last thirteen years. To be specific, we ask the following question in the enquiry process; Does Browsing intensity of Acacia drepanolobium have effects the tree morphological structure (galls and spines) which in turn affect the ants' colonization?

\section{Literature Review}

\subsection{Theoretical Framework}

There are a number of theories in place to explain woodland loss in particular areas. These theories include serial overgrazing by overwhelming livestock; swelling pest insects and pathogens numbers, and climatic change that particularly favour salinity and rainfall patterns. Each theory assumes a different cause and, by inference remedy. The proposed study is designed to test protection mutualisms that exist between ant and which have acted as reference and control systems for exploring wide variety and range of questions that are categorized in the in the fields of evolutionary biology and ecology.

The Ant-plant mutualisms of protection have long acted as tractable mechanisms and systems used for ascertaining plant defense theory aspects (Fonseca 1994, Heil et al. 2001). The symbioses of Myrmecophyte have even served with great reliability and frequency as models and samples for qassessing the conditional outcomes that come out of interactions among interspecies (Gaume et al. 1999) and comprehending the mutualisms and their evolutionary stabilities in the face potential ecological conflicts which often present conflicts of destabilizing potential (Yu, 2001). This study will also test an inducible response and reaction to the browsing pressure of mammals; whether the number of galls and thorns depend on the level of browsing pressure. Janzen (1966) and Madden (1988) theory articulates that ant symbionts display excellent efficiency when compared against the key African megafauna, and some species of acacia may have the energy allocation tendency geared to support the ant symbionts at the costs and the expense of other defences available. Besides, the Aggressive and hostile arboreal ants tend to preferentially act as a super nettle, as noted by findings of Brown (1960).

The theory of fire has for a long time been advanced an appropriate tool of managemet for encroaching and aggressively expanding Acacia drepanolobium (Wahungu, 2012; Pratt \& Gwynne, 1977; Dall, Maass \& Isselstein, 2006). Herbivore preferences for burned areas (Wahungu, 2010; Zavala \& Holdo, 2005) have been noted to persist for a period not less than two years following a fire incidence and this can be attributed to cause an imbalance in the acacia ant interaction Zavala and Holdo, (2005). Wahungu et al., (2009) examined the impacts of controlled and regualted fires on Acacia drepanolobium trees by monitoring and tracking of the growth and survival in research or experimental farms prior and following fire outbreaks or episodes. According to their findings, the tall trees were more poised to die from the ravaging effects of fire compared to the short trees, while the general densities and distribution of seedlings exponentially increased after fire incidences. This shows that fire kills some of the trees therefore breaking down the interaction of Acacia drepanolobium and Crematogaster ants' interaction. They also found out that despite the notable increase in densities of seedlings, the fire ravaged areas attracted huge counts of seedling eaters and predators, further decreasing seedling recruitment possibility into adult stage, there was a significant reduction of the mean heights of seedlings.

The Interspecific trade-offs theory regarding competitive ability has a vital role in the organization and natural rearrangement of the ant communities. (Holldobler \& Wilson 1990). For instance, trade-offs that determine resource location and domination abilities once such resources have been identified and located (Fellers 1987) often predispose to temporal and situational habit of ant species succession. The Spatial variation that has for decades been witnessed in resource abundance on the natural process of coexistence of ants and the general community structure (Davidson 1977; Kaspari 1996; Schooley et al., 2000) was, also within the scope and focus of the study. 


\subsection{Conceptual framework}

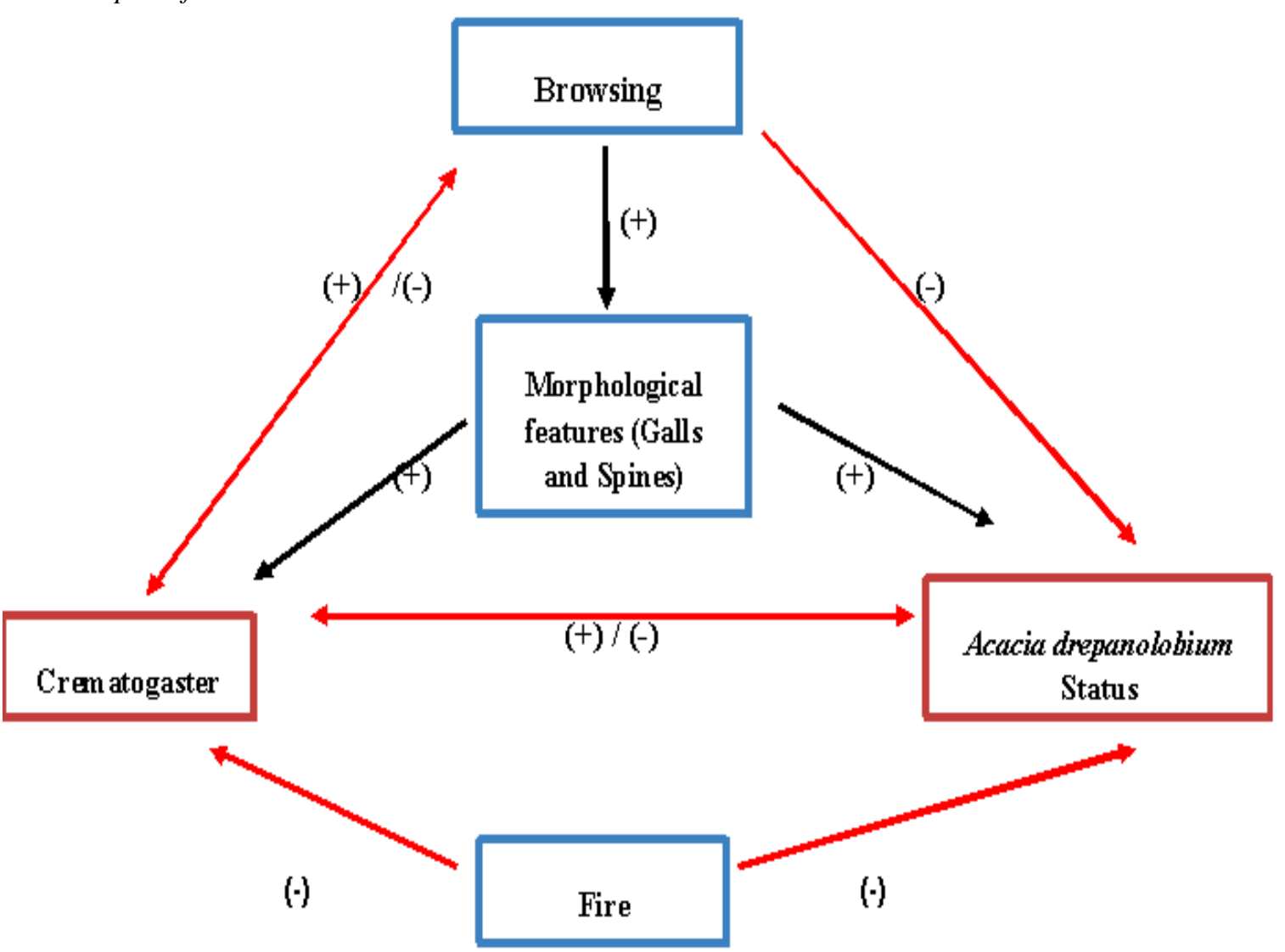

Figure 1: Conceptual framework model of factors affecting Acacia drepanolobium and Crematogaster ant's interaction (Source: Authors, 2020).

The positive sign (+) denotes and represents a positive relationship, the negative sign (-) represents a negative relationship while the single point arrow denotes a relationship between variables whereas double pointed arrow denotes two sided relationships between variables. The conceptual framework has three major components which were investigated: Browsing intensity, Morphological features of the Acacia drepanolobium tree and fire.

\subsubsection{Description of conceptual framework}

The study conceptualizes how the intensity of browsing will affect the tenancy dynamics of Crematogaster ants on the Acacia drepanolobium tree. The study aimed to statistically found out significant effect on Crematogaster ants and Acacia drepanolobium interaction. The conceptual framework also lays out how the intervening variables; browsing, fire, and morphological features of the tree affect the status of the trees.

The study conceptualizes that if browsing intensity is greater, then the status of Acacia drepanolobium will be appalling. The study aimed to find out browsing intensity ability to trigger the Acacia drepanolobium in hosting the most aggressive Crematogaster ant species in order to deter the browsers from 
feeding on the tree. Therefore, it was also conceptualized that by Acacia drepanolobium hosting aggressive ants' species, it will be protected thus adopt excellent status as aggressive and hostile arboreal ants have a tendency to function and double up as a super nettle, as advanced by Brown (1960) that will deter the browsers from harming the host tree. Earlier studies showed that plants that lack ants experience higher herbivory levels compared to the non-specifics with scanty or heavy ant colonies (reviewed in Davidson and McKey 1993) although it seems logical and reasonable to expect a translation of strong ant defense system into higher reproductive output of the affected plants.

This study also tested an inducible reaction and response to the browsing pressure of mammals; whether the total number of thorns and galls depend on the level of browsing pressure as Janzen (1966) and Madden (1988) theory articulates that ant symbionts tend to be more effective against the crucial and key African megafauna, and some species of acacia tend to allocate and spend energy in support of the ant symbionts while assuming other systems of defences. It was conceptualized in this study that greater browsing intensities might lead to dynamics of the tree morphological features by increased number of galls on the branch of Acacia drepanolobium tree which will be houses for the Crematogaster ants.

The inducible response to mammalian browsing pressures in regard to number of thorns on Acacia drepanolobium trees in the conservancy area of $\mathrm{Ol}$ pejeta was also tested, and it was conceptualized that the Acacia drepanolobium tree might allocate resources in having more thorn (spines) which also deter the browsers from harming the tree on order to maintain excellent status. Earlier studies found out that magnified and intense pressure of browsing emanating from mammals tend to start and induces a rise in both the total count and density of the resulting longer thorns (Young 1987; Milewski et al.1991).

It was conceptualized that fire will reduce the status of both Acacia drepanolobium tree and Crematogaster ants inhabit in the host trees. This study aimed to find out if fire kills some of the trees therefore breaking down the interaction of Acacia drepanolobium and Crematogaster ants' interaction. Wahungu et al., (2009) examined the effects of controlled fires on Acacia drepanolobium and they found out that tall and longer trees were more predisposed and likely to perish or die from the damaging effects of fire as opposed to shorter trees, while at the same time, the densities of seedlings exponentially increased following fire episodes and incidences.

2.3 Acacia drepanolobium status in Ol pejeta conservancy

Ol pejeta was initially established in 1998 as the Sweet Waters Game Reserve, which was $90 \mathrm{~km}^{2}$ fenced area containing among other species, three browsing megaherbivores; rhinos, elephants and giraffes. The reserve was completely surrounded by a live electric fence. There was a lot of browse and vegetation damage pressure on the habitat particularly on the whistling thorn (Acacia drepanolobium). This species is preferred by the three large herbivores. Since 2005, the reserve has been expanded into a $225 \mathrm{~km}^{2} \mathrm{Ol}$ pejeta conservancy (Wahungu et al., 2010).

The information and data gathered by volunteers of Earthwatch for thirty-six months (1999-2001) displayed clearly that the high concentration and densities recorded by giraffes and elephants had damaging effects on their Sweetwaters habitat. The drought that was witnessed between 1999/2000 even served to worsen this situation. A game-changing finding reported an exponentially increased elephant damage with deceasing rainfall owing to their switching of feeds and diets to browse from the traditional grass.

Birkett \& Wood (2005) even went ahead to collect data on the impacts of height-specific browse for a total of 1075 trees that belonged to the dominant species, the whistling thorn, Acacia drepanolobium. Elephants and rhinos were noted to have browsed a whopping $18 \%$ of these trees in just one year, a figure that took account of the removed or killed 5\%. High levels and intensities of giraffe browse were meted on the remaining trees together with low amounts of rainfall, resulting into merely $7.5 \mathrm{~cm}$ annual growth.

As suggested by Birkett \& Wood (2005) massive drought was witnessed in Kenya during the second year. Sweetwaters experienced record lowest rainfall affecting the growth, distribution, and subsequent browse behaviour and herbivory patterns. There was virtual cessation of tree and grass growth. Consequently, elephants changed diets to trees from grass and colonized areas traditionally and conventionally occupied by 
rhinos. There was a yearly increase from $2 \%$ to $5.8 \%$ in the overall trees removal rate. Some elephants, particularly the adult females, perished, but the browsing nature of giraffes and black rhinos conferred them a survival advantage (Birkett \& Wood, 2005).

In project's third year (Birkett \& Wood, 2005), there was a reduction in height of tress located in the reserve area. In initial 5 months following last measurement readings, the damage to trees had exceeded $13 \%$ of the population, taking into account the killed or removed $5.4 \%$ of the tree population. Some trees were killed by drought, but most importantly, elephants increased their habitat damage by supplementing their normal grass diets by aggressively browsing on Acacia drepanolobium, which is the whistling thorn tree. The Kenya Wildlife Service was on record for translocating a half of the affected elephants to Meru National Park which was deemed ecologically more favourable.

In the project's fifth year, the data proceeding elephant translocation indicated a drastic drop in tree mortality and damage that were previously induced by elephants (Birkett \& Wood, 2005). However, there was a rising trend in the extinction and death of trees due to the combined effects of the 1999/2000 severe drought and over-browsing by giraffes that deterred and hampered the processes of regeneration.

In 2007, Twenty-seven new rhinos were brought and released into section of the old ranch within the the Conservancy area. Currently cattle are now grazing alongside wildlife. Ol pejeta conservancy used prescribed burning to remove moribund grass, currently the issue is being dealt with through holistic grazing management of livestock where livestock are herded and concentrated in one section to graze and trample until all old grass is removed.

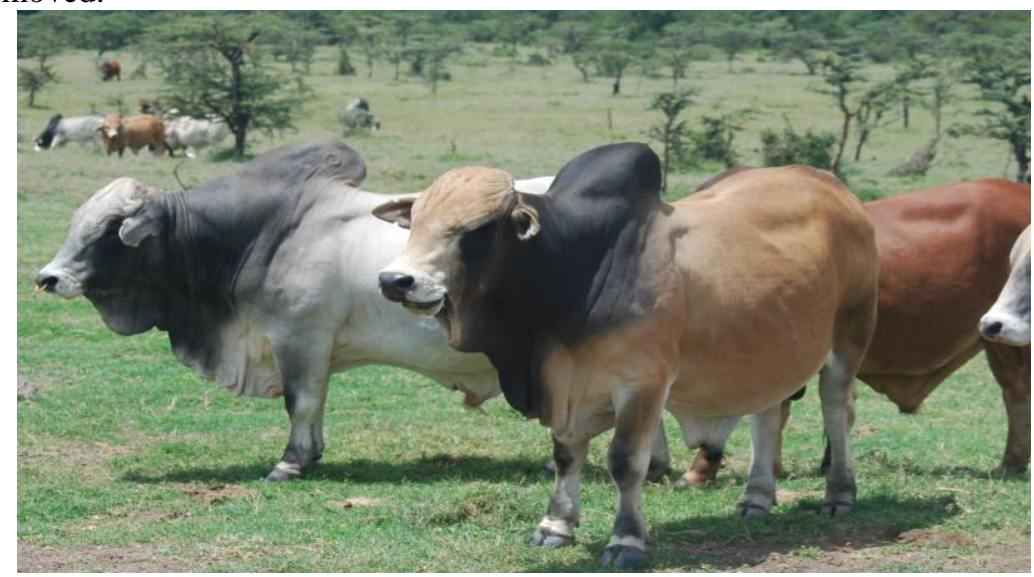

Figure 2: Cattle ranching in Ol pejeta conservancy and Acacia drepanolobium at the background (Source: Authors, 2020).

\subsection{Co-evolution of plant- ant relationship}

Drawing the attention of researchers and naturalists for over one century (Rettig, 1904) mutualisms have often been viewed as spectacular, interesting, perfect instances of biotic links and interactions that exert limited impacts on the ecological communities. Recent studies have, however, been of the opinion that opportunistic mutualisms that are derived from ant-plant interactions have played a leading role in food web restructuring in the canopies that exist in the tropical forests. Though confined to the tropics, the ant-plant symbiotic mutualisms cover species exceeding 40 ant genera and 100 angiosperm (Davidson and McKey 1993), and additionally form crucial and essential constituents of tropical environments and communities. The protection mutualisms of ant-plant relationships have acted as model and reference systems for enquiry into general interest questions in evolutionary biology and ecology. In the 1960s, for instance, studies centred on the myrmecophyte symbiosis proved beyond scientific doubt incidences that happened to plants immediately their herbivore defuses were neutralized and eliminated (Janzen 1966).

These elegant and insightful pieces of studies have stimulated subsequent research works on the co- 
evolution of plants and animals in several contexts. Since this time, the protection mutualisms of the ant-plant nature have acted as ideal systems for testing several aspects of plant protection postulation or theory (Fonseca 1994; Heil et al. 2001). Myrmecophyte symbioses have additionally served with admirable frequency and consistency as models and oints of references for conditional outcomes examination in interactions that occur within species (Gaume et al. 1999) and complete understanding of the existing the evolutionary stability regarding mutualisms that concurrently occur with potentially destabilizing and interfering conflicts ( $\mathrm{Yu}$ 2001). They have recently gained prominence in studies on coexistence between species (Palmer et al. 2002, Yu et al. 2001), the structure of food webs (Letourneau and Dyer 1998), and other topics and themes contained in the vast discussion of community ecology. The swollen thorn acacias of African descent have attracted massive research, postulations, and unending speculations regarding the relationships and links with their natural inhabitants (Monod and Schmitt 1968; Hocking 1970; Madden and Young 1992; Davidson and McKey 1993).

Hocking (1970), in his paper went ahead to describe the rich and interesting invertebrate fauna that is closely associated with extend of symbiosis, and even suggested that a variety of ant species displayed mutual exclusivity, without paying attention to quantitative and numerical descriptions of variations that existed among the ant inhabitats. On record, only Davidson and McKey (1993) give direct address to the prevailing question of coexistence and mutualisms that exist in different acacia-associated ants. The inherent ability and function of indwelling ants to protect and defend acacias against provided herbivory by large mammals is an often assumed phenomenon(Hocking 1970; Coe and Beentje 1991), although it still has preliminary supporting evidence (Janzen 1967; Madden and Young 1992), and thorns have been postulated to assume a more crucial role here in execution of this function (Young 1987; Milewski et al. 1991).

The relationship derived from the ant-plant protection is an ideal instance of mutualism (Bronstein 1998). Classically, plants confer several potential gains and benefits to ants, which include rewards of foods and a space for nesting (Vasconcelos, 1991). In return to this, ants tend to provide shield and protection from herbivory by large mammals(e.g., Janzen 1966; Davidson and McKey 1993; Heil et al. 2001) or even diseasecausing pathogens (Letourneau, 1998), pruning done to adjacent plants to eliminate and avoid overlap other neighbouring plants has been found to interfere with its own growth and devopment (Janzen 1966; Davidson and McKey 1993, Federle et al. 1998), and enrichment by nutrients (Janzen 1966; Treseder et al. 1995; Sagers et al. 2000). Out of all proposed services, herbivory still stands out as the most recognized and documented; as there are higher extends and levels of herbivory in plants without ants that their conspecifics with ants (reviewed in Davidson and McKey 1993). Although it is correct and reasonable to anticipate a strong antinduced defense of plants to miraculously increase the reproductive output of such plants.

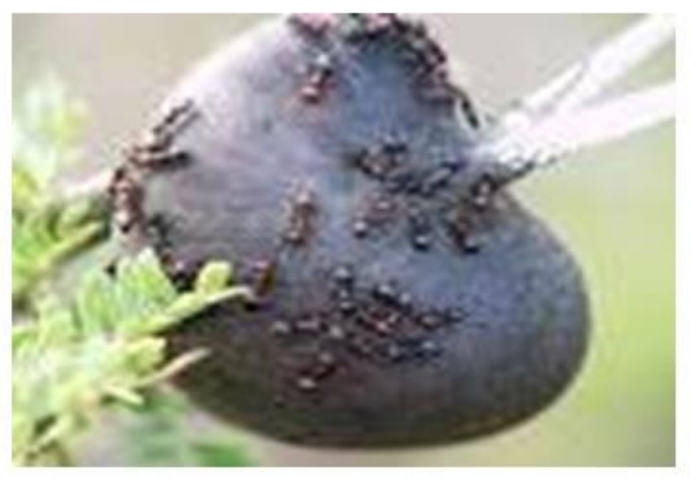

(A)

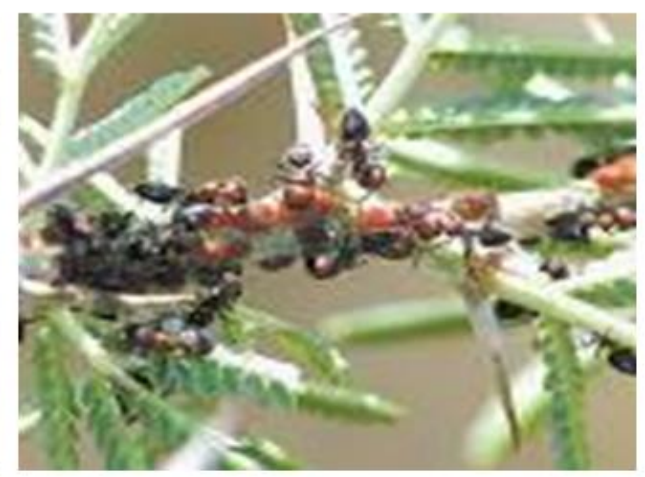

(B)

Figure 3. (A) Crematogaster ants on Acacia drepanolobium gall. (B) Crematogaster ants on a branch of Acacia drepanolobium tree (Source: Authors, 2020). 
The scientific proof and fact that trees use more resources and energy in ants and thorns point to the crucial interactions between these factors and players that bolters the defense mechanism than either of the palyers on their own. The armature and narrative of sharp, long horns is a feature shown by ant-acacia together with other species of the acacia family. However, when the emphasis is on ant-acacias, sevral thorns have swollen bases, areas that are used by ants to derive a living and even rear their brood. There are uncertain effects exerted by the in the plant defense against the mammalian browsers (Cole 1986; Potter and Kimmerer 1988). In A. drepanolobium, for instance, mammals display an intense pressure of browsing that trigger an increase in density, concentration, and number of thorns (Young 1987; Milewski et al. 1991), further stressing that thorns participate in plant protection and defense. In another species of Acacia like Acacia tortilis an increased thorn density guards the twigs but not automatically the plant leaves from goat browsings (Gowda 1997). Cooper and Owen- Smith (1986) demonstrated the effectiveness of thorns in slowing down the rate of feeding by browsing mammals like lesser kudu, impala, and goats even though these mammals compensate for this protective feature by extensive feeding for extended periods. Derek Madden and Truman Young (1992) studied the behaviour of feeding of free-ranging giraffes and demonstrated a strong sensitivity developed towards ants of Crematogaster family living in A. drepanolobium exhibited by giraffe calves, and feeding for essentially limited and shorter times on trees infested by a massive number of more aggressive ants.

Larger browsers are more affected by thorns as opposed to smaller browsers. For example, Foster and Dagg (1972) and Pellew (1984) demonstrated that the overall rates of ingestion of giraffes (Giraffa Camelopardalis) remain unaffected by thorns belonging to A. drepanolobium. Thus, although thorns have appeared to be an inducible reaction and response to the browsing pressure of mammals, their real and actual effectiveness and efficiency when used as anti-herbivore defence and protection against specialized and large herbivores remain unclear and inconclusive.

Another inborn feature of ant-acacias is possession of the extra-floral nectary glands located on the petioles of the leaves avail nutrients to the ants (Knox et al. 1986). Some species of ant-acacias originating from South American also secrete beltian bodies which are protein- aceous that the ants act to harvest (Janzen, 1966). The African ant-acacias conspicuously lack these bodies. The ants have been famous for guarding and protecting the plant from browsing insects and mammals (Janzen 1966; Hocking 1970; Knox et al. 1986; Schupp 1986; Madden and Young 1992). Interestingly, the Australian region lacks ant-acacias and thorns despite the Acacian genus diversity seen there, nor are there numerous browsing insects and mammals as seen in South America and Africa. As such, Brown (1960) proposed that the ants played a role in defense and protection against browsing mammals that led to change and evolution of the ant-acacia link and relationship and even suggested that this was the main gain that the plant enjoyed from such association or interaction.

\subsection{Plants Having Hollow Structures}

There are natural hollow structures in many plans that host a variety of insects. Out of all insects, only a few are classified as true myrmecophytes such that they derive a symbiotic link and relationship with inhabiting ants, harbouring and hosting them in the domatia, which represent the preformed cavities and providing food sources and nutrients (Joli- vert 1996). Bequaert (1922) quotes and makes reference to 262 myrmecophytic species around the world, whilst Benson (1983) quotes and makes use of 465 species. The genus Acacia provide the most classic and best known examples (Leguminosae; Mimosoideae) in Africa (Janzen 1966) and South America (Monod and Schmitt 1968; Hocking 1970), which are the ant-acacias.

\subsection{Plants Defenses to Herbivory}

Grasses register frequent herbivory compensation (McNaughton 1983; Varnamkhasti et al.1995). herbs have also recored compensatory growth mechanisms (Paige 1992; Alados et al. 1997, Cebrian et al. 1998; Lennartsson et al. 1998), shrubs (Tolvanen and Laine 1997; Oba et al. 2000), and trees (Kudo 1996; Bergstro"m et al. 2000) have also responded the same. Timing, extent and types of herbivory events dictate herbivory responses and resource availability in the surrounding to support re-growth and regeneration effects 
respectively (Mc-Naughton 1983; Rosenthal and Kotanen 1994), and the feeding and grazing: history of browsing the plant under study (McNaughton 1983; Paige 1992).

Increasing evidence from experimental and descriptive research show that plants subjected and exposed to herbivory have beefed-up defenses. Developed insect-attack resistance can be deduced from increased physical and chemical defense productions, or diminished fitness of the insects which are herbivorous (Rhoades 1983; Schultz and Baldwin 1982; McNaughton and Tarrants 1983; Karban 1983; Karban and Carey 1984). Such plasticity installed in plant defense mechanisms permits diversion of resources by plants and utilization only when needed, increasing efficiency of resource alloaction. Evidence supports that prickles and thorns successfully deter herbivory. Feeding rates scrutiny and examination on armed and unarmed tress in the African savannah region demonstrated that thorns significantly reduced browsing rates by large animals (Cooper and Owen-Smith 1986). Experimentally, when the thorns were removed from Acacia species, mammalian herbivory rates were greatly (Cooper and Owen-Smith 1986) and prickles obtained from the thistle Carduus keniensis (Young and Smith 1987). Abrahamson (1975) observed that thorns contained on Rubus shrubs in browsed locations were sharper and longer than those from non-browsed areas. This latter developed probably due to an induced response.

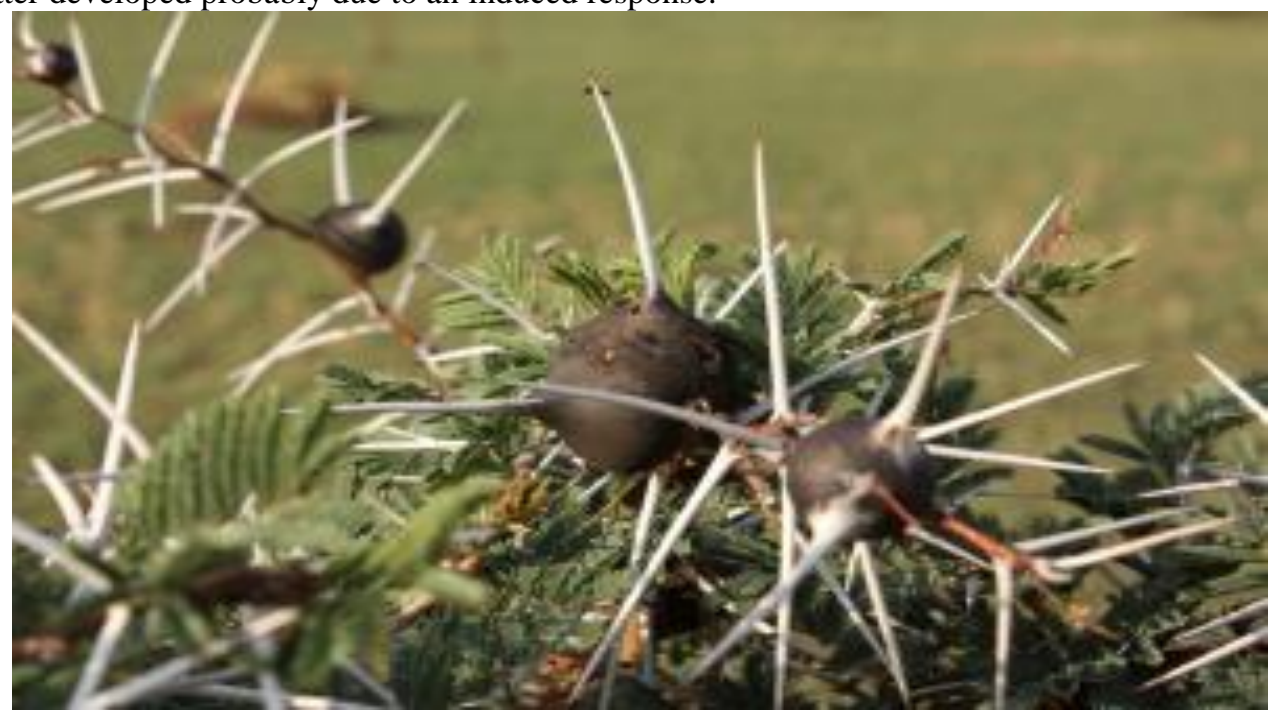

Figure 4. Acacia drepanolobium image showing galls and spines used for defense (Source: Researcher, 2020).

\subsection{Other Importance of Acacia Ants}

The Patas monkeys of East Africa have an estimated 30-40\% of their diets made up of ants, and they are fed on all year-round (Isbell, 1998). Hocking (1970) made an estimation that in the ecosystem feature of Acacia drepanolobium where it tends to occupy the black cotton soils in East Africa regions, in excess of 4, $000 \mathrm{~kg}$ of ant biomass can be located per every square kilometre. Thus, they are likely to exert profound effects on their ecosystems as predators of their prey which are, as eaters of plant nector, as tenders of insects with scale, as guarders and protectors of their tree hosts, and as food and source of nutrients for their own predators.

\subsection{Controlled Burns}

In the ecosystems of African Savannah, fire has been a widely studied event and phenomenon (O’Connor, 1985; Sabiiti, Wein and Edroma, 1991; Higgins, Bond and Trollope, 2000; Govender, Trollope and Van Wilgen, 2006), but the impacts it exerts still remain less understood. In several rangelands across the world, fire has been utilised as a tool in the management of vegetation occurring in the range in so many 
ways: to decrease cover of bush, influence variations in composition of species, to enhance and improve the overall quality of forage to animals, and to control the number of pathogenic pests. On its own or in combination with occurences and factors like soils, climate, and herbivory, fire guides vegetation changes (Whelan, 1995). Fire is the proposed as effective management tool for encroaching A. drepanolobium (Pratt and Gwynne, 1977; Dall, Maass and Isselstein, 2006). In Ol pejeta controlled burns have been used for reduction of moribund grass for pasture quality improvement available to both wildlife and livestock until 2003 (Wahungu et al., 2010).

2.8.1 Fire Mortality and Fire Damage On Acacia

Wahungu et al, (2011) have established that fires at Ol pejeta stimulate seedling regeneration for $A$. drepanolobium but suppress recruitment into adult trees. They observed that burning reduces the amount of grass cover and opens up the seedlings to predation, because burned areas become hotspots for grazer feeding aggregations. Wahungu et al., 2010 also observed torching or burning kills mostly adult trees that may already be suffering from water stress thereby reducing flowering. Dublin et al. (1990) and Pellew (1983) were in concurrence that fire associated with big and large herbivores determines the state (mixed or grassland) of existence of a savannah vegetation. Higgins et al. (2000) came up with a model to explain co-existence between tree and grass solely based on fire responses by using of equations which were partly derived from complete measures of response of Acacia to varying intensities and frequencies of fire in the region of South African Savannahs. The paper on classic modelling by Pellew's (1983) brought into concept the diversty and differences of impacts (fire ,elephants, and giraffe) on A. tortilis. Generally, fires in savannah fires traditionally cause top and massive kill in taller species (Wahungu, 2010; Trollope, 1984) rather than the believed total mortality, and in several instances reverse development of trees to seedling stage from through formations of re-sprouts (Wahungu, 2010). Most species in the woody savannah, that probably include most acacias, have the capability of resisting re-sprout and fire to certain degrees. Clearly, most Acacia species display a variety of fire responses and different reactions from varying size classes. Pellew (1983) postulated that herbivores tend to worsen and exacerbate the fir impacts by keeping and restraining a huge percentage of the total population within the fire trap. He observed that the process of regeneration; even among the species which are putatively sensitive to fire is chiefly derived from rootsock. For Ol pejeta Conservancy, Wahungu et al (2012) found that overall; fire was detrimental to the survival of A. drepanolobium as it resulted into encroachment of Euclea divinorum bushes into A. drepanolobium habitat. The hugely felt need is for more studies on effect of fire on Crematogaster ant and Acacia drepanolobium interaction but not merely the rates of adult mortalities, and this still remains undone.

\section{Methodology}

\subsection{Description of Study Area}

This research or study was carried out in Ol Pejeta Conservancy (OPC) that is found in central parts of Kenya, two hundred and thirty kilometres to the north direction of Nairobi, next to Nanyuki, and right on the plateau of Laikipia that is situated between the Aberdare Mountains and Mt. Kenya, a 364- $\mathrm{km}^{2}$ area. The Conservancy of Olpejeta (which was previously known as Sweetwaters Game Reserve) is found or located at an altitude of $1800 \mathrm{~m}$ right on the equator $36^{\circ} 56^{\prime} \mathrm{E}$. The nature of the vegetation is Euclea scrub woodland, riverine woodland, mosaic pattern of grassland, andAcacia woodland (Birkett, 2002). The Conservancy is located on the southern parts and is also arguable the wettest area in all regions of the greater SamburuLaikipia habitat and ecosystem with a mean annual rainfall of $900 \mathrm{~mm}$ and also a bimodal pattern of rainfall.

Other large or huge mammal herbivores that were found at the site of the study include steinbucks (Raphicerus campestris), elephants (Loxodonta africana), cape buffalos (Syncerus caffer), giraffes (Giraffa camelopardalis), elands (Taurotragus oryx), Grevy's zebras (Equus grevyi), Burchell's zebras (Equus burchelli), Beisa oryx (Oryx beisa), Grant's gazelles (Gazella granti), Jackson's hartebeests (Alcelaphus buselaphus jacksoni), Waterbuck (Kobus defassa), and domestic cattle. Predators in the list included wild dog (Lycaon pictus), Lion (Panthera leo), Silver-backed jackal (Canis mesomelas), cheetah (Acinonyx jubatus), 
Spotted hyena and leopard (Panthera pardus) (Crocuta crocuta). Primates on their part include Patas monkey (Erythocebus patas), Olive baboon (Papio anubis), Vervet monkey (Cercopithecus aethiops), and Lesser bushbaby (Galago senegalensis) (Wahungu et al., 2009).

Two species, multi-stemmed type of shrub Euclea divinorum and the whistling thorn tree $A$. drepanolobium were noted to dominate most areas of the conservancy (Birkett, 2002). Currently and presently, the whistling thorn acts as one of the chief foods that is preferred by the black rhinoceros, and making up in excess of 75\% of its meals or diet this model of conservancy (Birkett, 2002; Wahungu et al., 2012). Acacia drepanolobium has been noted to have undergone excessive browsing pressure from drought, elephants, giraffes, and rhinos (Birkett, 2002).

\subsection{Study System and Methods}

In order to measure interaction between Crematogaster ants and Acacia drepanolobium under varied browsing pressures. There was a need to choose plots with varied browsing intensities for this study, therefore some plots were purposefully chosen as control- (Chimpanzee Sanctuary) where there was no browsing at all. Some plots in the ranch were also purposefully chosen where browsing intensity is intermediate. And finally some plots in the reserve were also chosen due to the extensive and intensive nature of browsing. The seedlings and trees of of Acacia drepanolobium that were obtained from twelve out of the set-up 30 plots in 1998 (See Birkett, 2002; Birkett \& Stevens-Wood, 2005) that were randomly selected were visited and used foir the study as stated two (2) in a Chimpanzee Sanctuary where elephant, giraffe and rhino are excluded (control), six (6) in the reserve and four (4) in the Ranch. An aluminium tag which was numbered was used to identify each tree and then fixed to trees that had heights above one metre using nails and to seedlings less than one-metre-tall by a wire covered in plastic. Initially, every plot had between 40 to 60 tagged and named trees that were chosen as stratified sample of seven classes of height. Information or data collected by Earthwatch International was also used to show trend of Acacia drepanolobium trees colonization by mutualistic ants from 1999 to 2011.

The input used for each tree was as follows: The tag number of the tree was recorded; the tree heights $(\mathrm{cm})$ were recorded up to a measured accuracy of $2 \mathrm{~cm}$ by use of a Dynamis Telescopic Measuring Rod (Stanton Hope, 1998 in Wahungu et al., 2009) that allowed extension to $7 \mathrm{~m}$. These trees were placed in to height bands $<0.5 \mathrm{~m},>0.5 \mathrm{~m}<1 \mathrm{~m},>1 \mathrm{~m}<1.5 \mathrm{~m},>1.5 \mathrm{~m}<2 \mathrm{~m},>2 \mathrm{~m}$. Mean number of galls on $100 \mathrm{~cm}$ branch of Acacia drepanolobium tree colonized by different mutualistic ants was recorded as well as mean number of spines on $100 \mathrm{~cm}$ branch of Acacia drepanolobium tree colonized by different mutualistic ants was also recorded.

The primary and chief symbionts of A. drepanolobium in the East Africa region are the four species belonging to acacia ants. Four species of acacia-ants are the primary symbionts of A. drepanolobium in East Africa (Hocking 1970), and all of them have been found to co-befall at the levels of fine spatial scales in our study location (Young et al. 1997, Palmer et al. 2000, Palmer 2003). Crematogaster nigriceps, Tetraponera penzigi, and C. mimosae stay and nest purely and exclusively within the sprouted thorns, whereas Crematogaster sjostedti has been noted to inhabit the stem and trunk cavities created by beetles which are wood-boring (Palmer et al. 2008a).

Measurements were taken and recorded in the field of study making use of a US Robotics 3ComPalmPilot Professional that had a software provided by the University of Kent (Pascoe, Morse \& Ryan, 1998). Data were then downloaded from the Palm Pilot into Data was entered into Excel spreadsheet, coded appropriately and then and later analyzed using the $20^{\text {th }}$ version of the Statistical Package for Social Sciences version (SPSS Inc., Chicago, IL, USA). The data obtained were then processed into quantitative tables to give a comparative analysis for response obtained. Size class distributions of the reserve, Ranch and control were compared by means of Analysis of variance (ANOVA), and other relevant parametric statistics per the research objectives. Some data were compared with secondary data obtained from Earthwatch Institute Research project reports to justify the need for corroboration. 


\section{Presentation, Interpretation and Discussion of the Findings}

\subsection{To Establish Whether Variability in Browsing Intensities of Acacia drepanolobium Affect the Type of} Symbiotic Ants' Colonization.

The assessment on whether differences in herbivory damage or herbivore abundances explain the observed effects on Acacia drepanolobium and Crematogaster ant mutual performance was carried out. A total of 593 Acacia drepanolobium trees were studied. Out of a combined total 29\% (173) of the Acacia drepanolobium trees did not host symbiotic ants, $31 \%$ (186) Acacia drepanolobium trees were associated with Crematogaster mimosae and 32\% (192) were associated with Tetraponera penzigi while 5\% (32) Acacia drepanolobium trees were occupied with Crematogaster nigriceps and only 2\% (10) Acacia drepanolobium trees were inhabited by Crematogaster sjostedti. There was a strong variation and difference in the four acacia ant species in terms of overall extents and levels of tenancy while responding to varied pressures of browsing; Tetraponera penzigi and Crematogaster mimosae were found to be the most abundant/frequently observed ant species occupying trees in the reserve where there is intensive browsing (Reserve) and the ranch with medium browsing intensity. Crematogaster mimosae ant species recruited strongly to disturbances, aggressively defending trees from the researchers who simulated browsing. The number of trees associated with ants was relatively low in plot where there is no browsing at all (Chimpanzee Sanctuary where elephant, giraffe and rhino are excluded). (Figure. 5; ANOVA $F=6.497, \mathrm{df}=2 \mathrm{P}=0.002$ ). We performed bivariate analysis using Pearson Correlation and the results showed that $\mathrm{Ol}$ pejeta conservancy varied browsing intensities was significantly correlated to symbiotic ant type (Correlation coefficient 0.088 significant at the 0.05 level (2tailed).

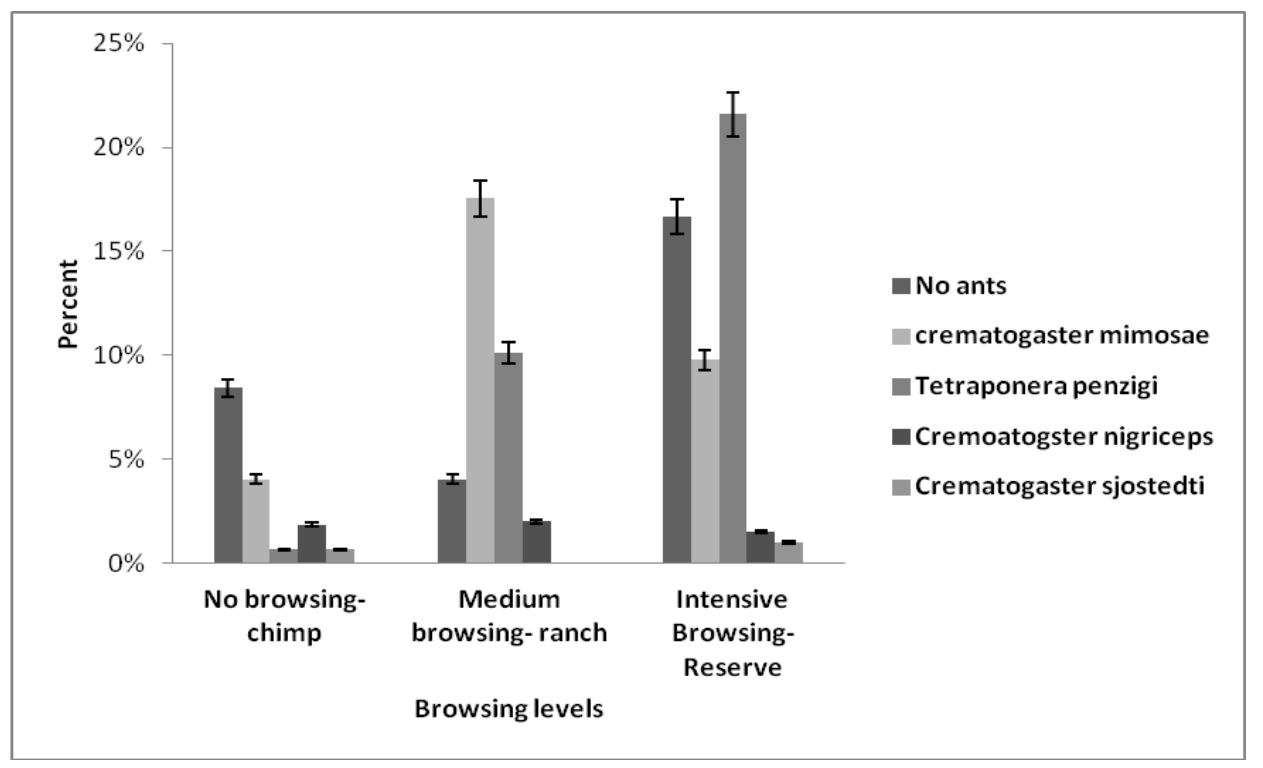

Figure 5: Frequency of Acacia drepanolobium trees colonized by mutualistic ants under varied browsing pressures at $\mathrm{Ol}$ pejeta conservacncy between January 2009 and October 2011. (Error bar = SE). (Source: Researcher, 2020). 


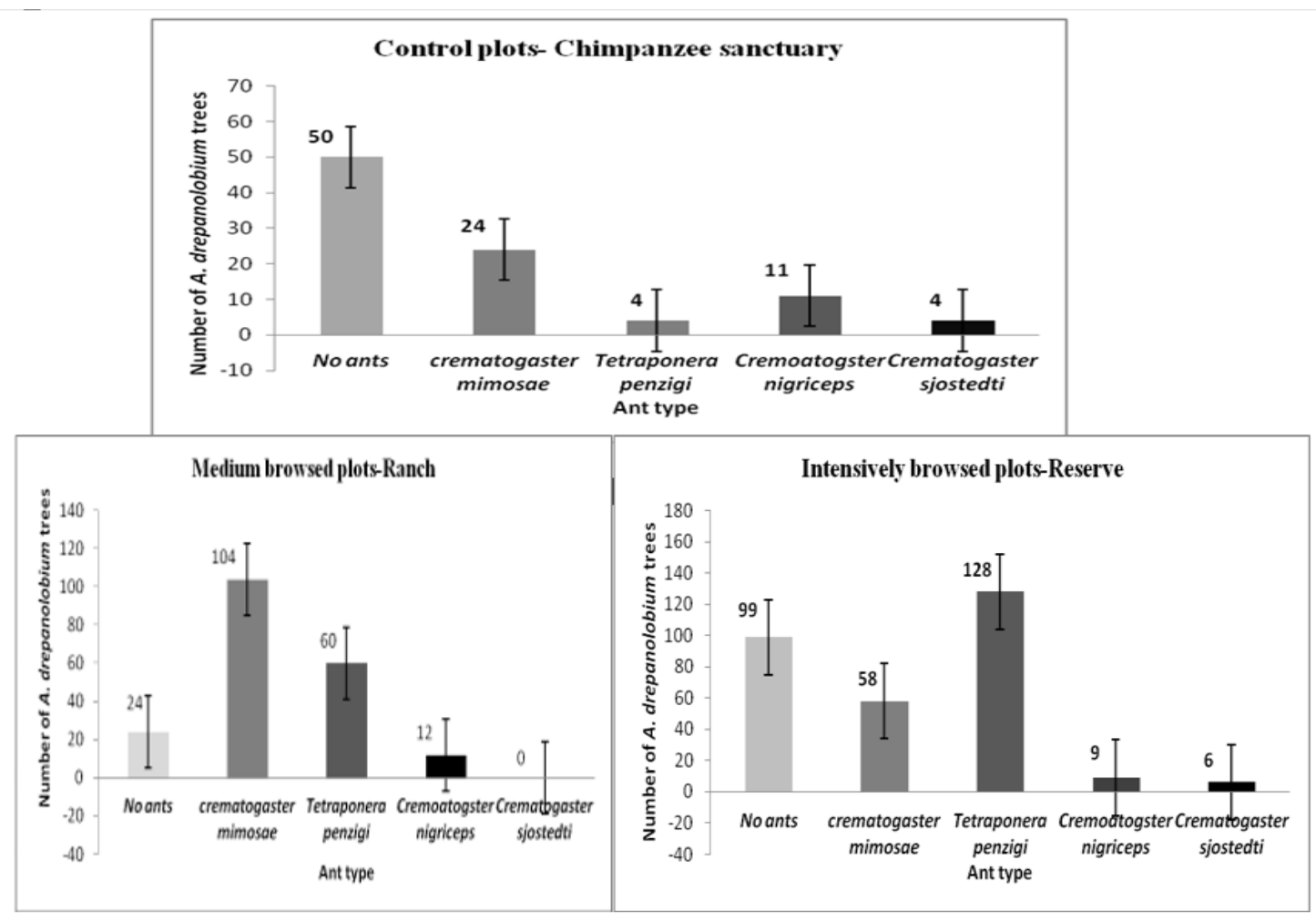

Figure 6: Frequency of Acacia drepanolobium trees colonized by mutualistic ants under varied browsing pressures (control-chimpanzee sanctuary, Medium browsed - Ranch and intensively browsed- Reserve plots) at Ol pejeta conservancy between January 2009 and October 2011. (Error bar = SE). (Source: Researcher, 2020).

This analysis (Figure 6) indicates that the browsing intensities dictate the type of symbiotic ant dominating the A. drepanolobium tree. Most aggressive Crematogaster ant's species are found in highly browsed sites (reserve) of the conservancy i.e. Crematogaster mimosae occupying 52\% of the total trees in the medium browsed plots whereas Tetraponera penzigi were found to be the most abundant/frequently observed ant species occupying trees in the reserve at $43 \%$ of the total number of trees where there is intensive browsing (Reserve). 


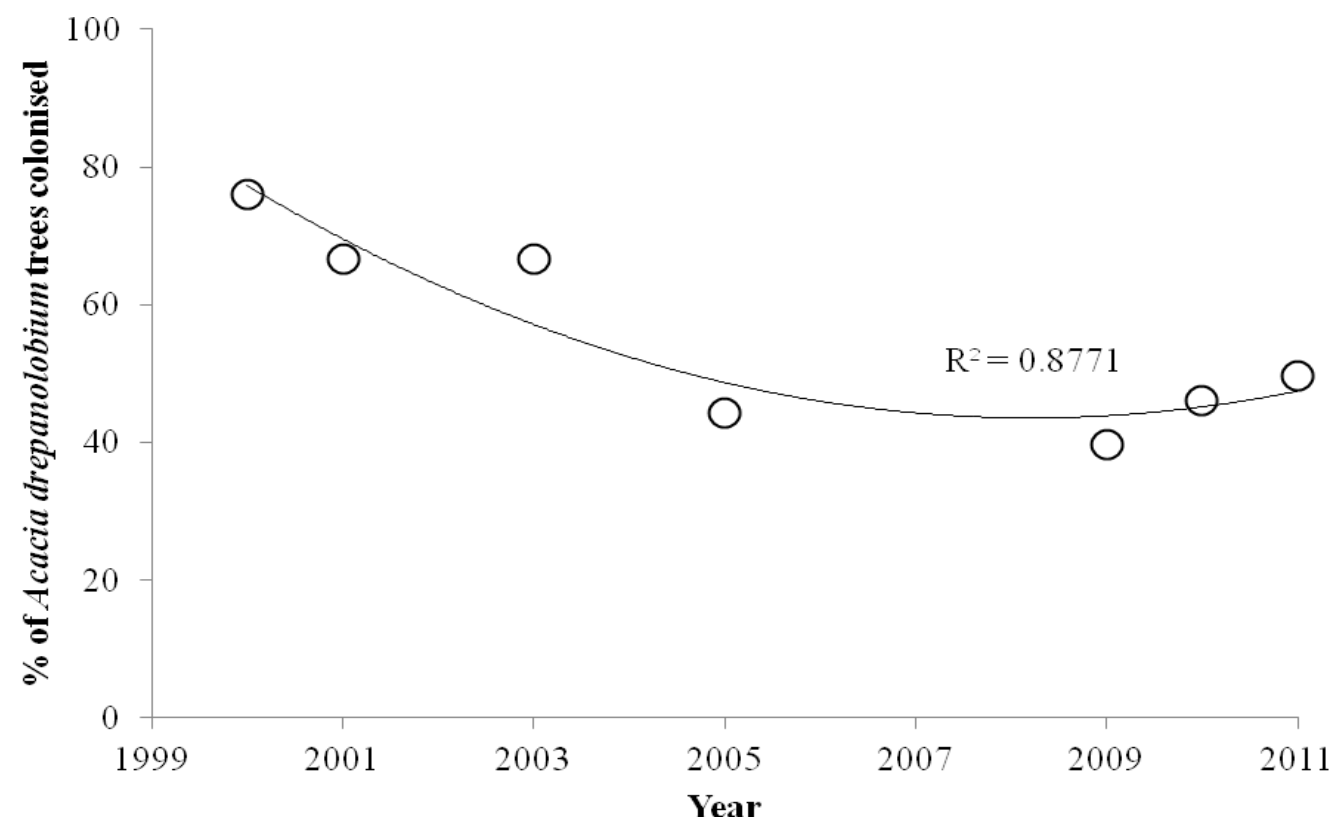

Figure 7: Trend of Acacia drepanolobium trees colonization by mutualistic ants from 1999 to 2011 (Source: Authors, 2020).

Figure 7 demonstrates that there has been a steady decline of colonized A. drepanolobium trees by symbiotic ants from 1999 to 2011. In 1998 the reserve was completely surrounded by an electric fence and

there was a lot of browse and vegetation damage pressure on the habitat particularly on the Acacia drepanolobium since this species is preferred by the three large herbivores this explains why the percentage of trees colonized by symbiotic ants in 1999 to 2000 was high. In 2005, the reserve was expanded into a $225 \mathrm{~km}^{2}$ Ol pejeta conservancy (Wahungu et al., 2010).

4.2 Establishing existence of Partitioning by different species of mutualistic ants inhabiting Acacia drepanolobium of different height classes.

Acacia drepanolobium trees were classified into different height classes: $1(0-50 \mathrm{~cm}), 2(51-100 \mathrm{~cm})$, $3(101-150 \mathrm{~cm}), 4(151-200 \mathrm{~cm}), 5$ (Above $201 \mathrm{~cm})$. Results indicate that there was partitioning by different species of mutualistic ants demonstrated by inhabiting trees of different height classes. Type of ants occupying different height classes of Acacia drepanolobium differed significantly $(\mathrm{F}=16.547, \mathrm{df}=4, \mathrm{P}<0.05)$ Figure 7. Bivariate Pearson Correlation analysis also indicated that the Acacia drepanolobium tree height was significantly correlated to symbiotic ant type colonizing the trees at 0.01 level (2-tailed) correlation coefficient 0.233 .

Most of the trees of height 1.6-2 meters were colonized by $C$. mimosa and $C$. sjostedti ants species, whereas the tree of height more than 2 meters were mainly colonized by Tetraponera penzigi ants. And Crematogaster nigriceps preferred to colonize Acacia drepanolobium trees of height 1.1 to 1.6 meters (Figure 8). 


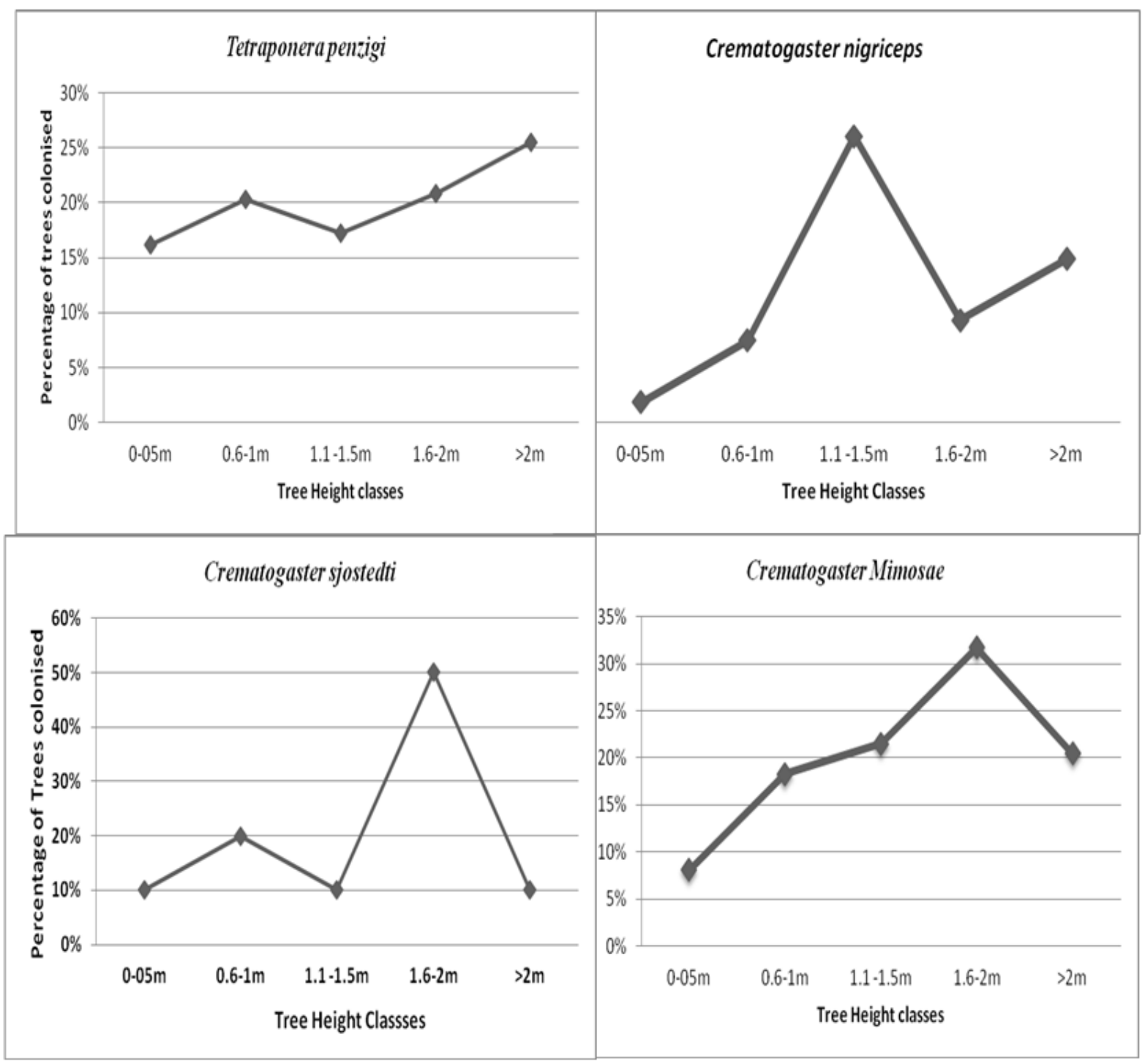

Figure 8: Representation of different height classes of A. drepanolobium trees colonized by four different species of mutualistic ant (Crematogaster mimosa, C. sjostedti, C. nigriceps, Tetraponera penzigi) (Source: Authors, 2020).

4.3 Establishing effect in variability of browsing intensities on A. drepanolobium morphological characteristics (number of galls and spines).

This study tested an inducible reaction and response to browsing mammalian pressure; whether the count and number of galls and thorns depend on the level of browsing pressure. Janzen (1966) and Madden (1988) theory articulates the effectiveness of ant symbionts against essential and key African megafauna, and some identified species of acacia species may actually transfer or allocate energy to support the symbionts of ant and ignore other systems of defense. Arboreal ants which are aggressive may carry out the role of super nettle, as proposed by Brown (1960). 


\subsubsection{Effect of Varied Browsing Intensities on A. Drepanolobium Number of Galls}

The number of galls differed greatly in plots with varied levels of browsing. The numbers of galls were found to be higher in A. Drepanolobium trees found in intensively browsed plots (reserve) compared to those in less browsed plots in the ranch as well as to plots in the chimpanzee sanctuary where there was no browsing at all. (Figure. 9; ANOVA $F=384.708, \mathrm{df}=2, \mathrm{P}<0.05$ ). Pearson Correlation bivariate analysis results showed that $\mathrm{Ol}$ pejeta conservancy varied browsing intensities was significantly correlated to mean number of galls on $100 \mathrm{~cm}$ branch of Acacia drepanolobium tree (Correlation coefficient 0.212 significant at 0.01 level 2-tailed).

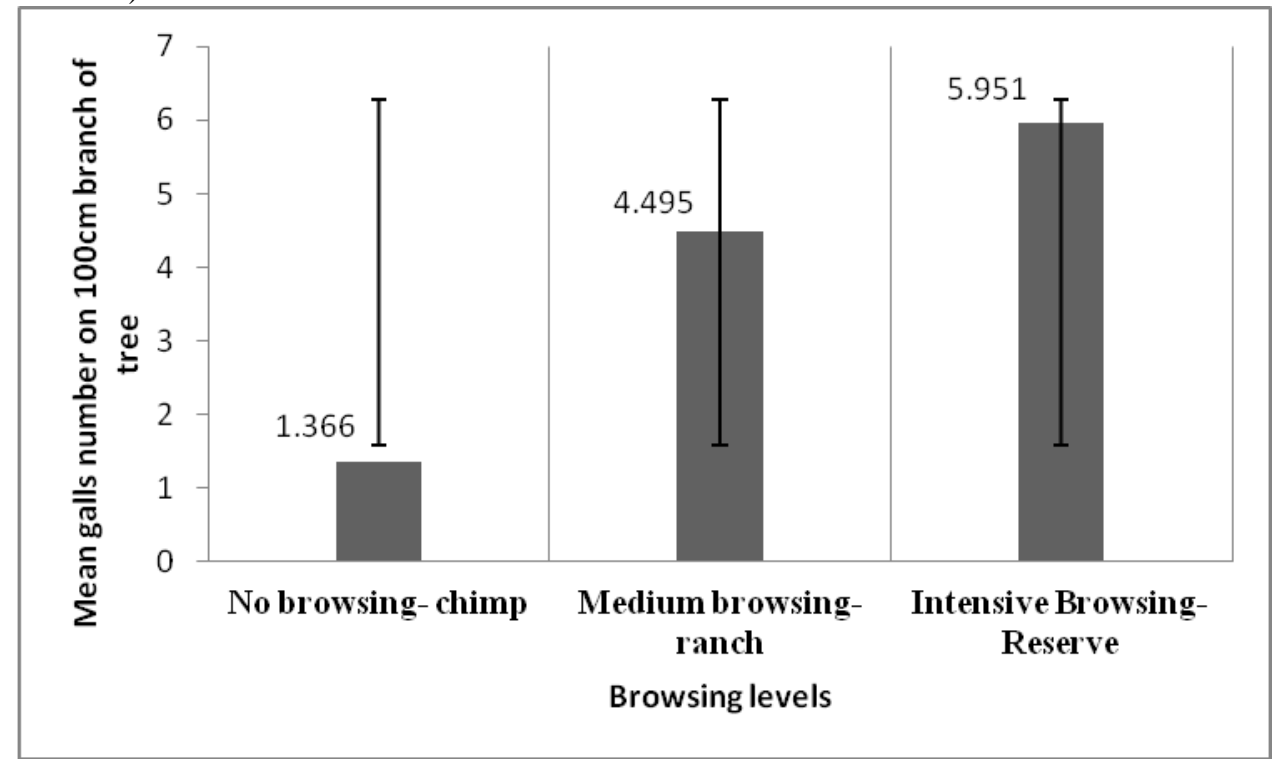

Figure 9: Representation of mean and Standard deviation of galls number on $100 \mathrm{~cm}$ branch of Acacia drepanolobium tree in different browsing pressures in O1 Pejeta Conservancy between January 2009 and October 2011 (Error bar = SD). (Source: Authors, 2020).

\subsubsection{Symbiotic ant type and the number of galls on Acacia drepanolobium trees}

It was also noted that there exists a significant difference in symbiotic ant type and number of galls on Acacia drepanolobium tree. $\mathrm{F}=12.905, \mathrm{Df}=4, \mathrm{P}<0.05$. Figure 10. It was observed that the Acacia drepanolobium had many galls to house $C$. mimosa and $C$. nigriceps as compared to galls for Tetraponera penzigi and $C$. sjostedti ant species. The mean number of galls on Acacia drepanolobium hosting C. Mimosa was $5.458 \pm 1.764$ which offer strongest symbiotic relationship, aggressively defending trees from herbivores while relying heavily on swollen-thorns for shelter and feeding off of nectar produced by glands near the base of leaves. The mean number of galls of Acacia drepanolobium trees hosting C. nigriceps was 5.100 \pm 2.885 . In other words, many galls were associated with most aggressive ant specie type. 


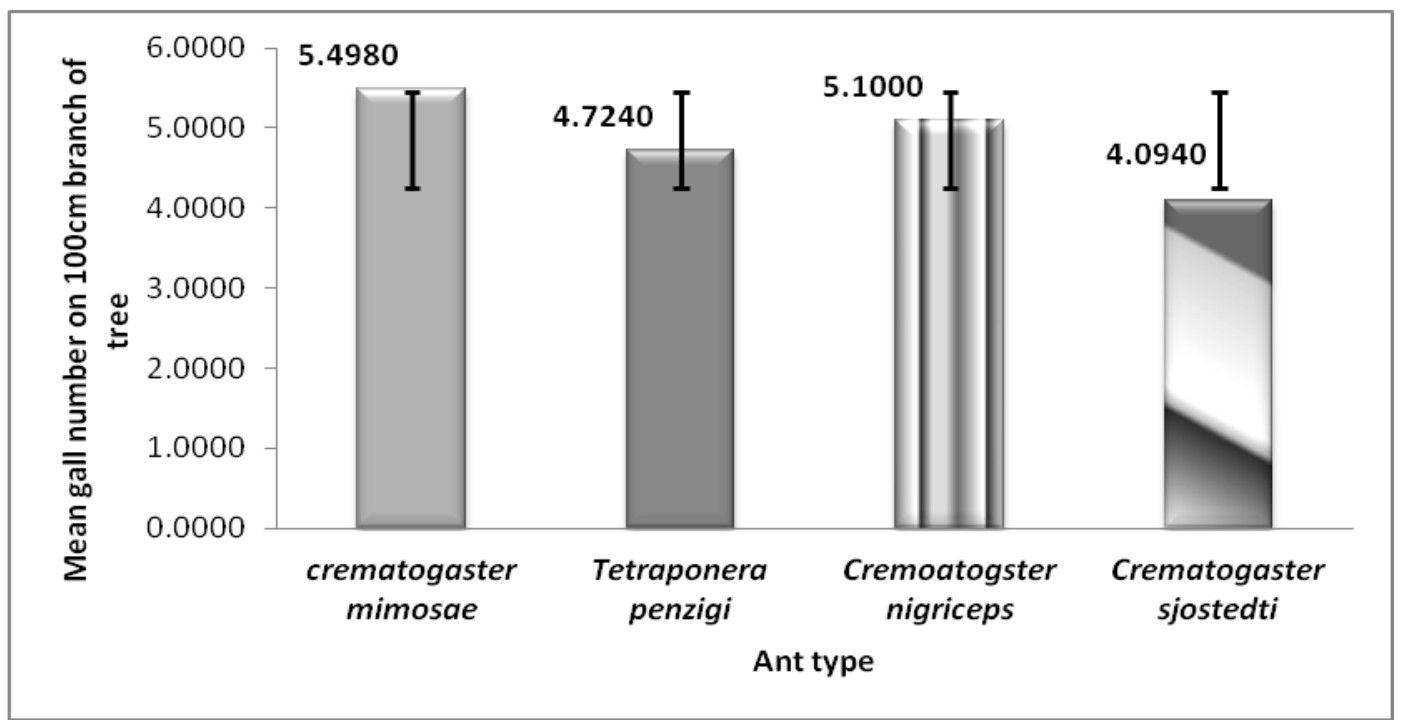

Figure 10: Representation of mean number of galls on $100 \mathrm{~cm}$ branch of Acacia drepanolobium tree colonized by different mutualistic ants in OlPejeta Conservancy between January 2009 and October 2011 (Error bar = SD). (Source: Authors, 2020).

Comparing the number of galls on A. drepanolobium branch and the presence of mutualistic ant species, results indicate that $C$. nigriceps and $C$. mimosae inhabit trees with more than $5 \mathrm{galls} / 100 \mathrm{~cm}$ branch while $C$. sjostedti ants were found on trees with least number of galls. This can be attested to by the fact that C. sjostedti don't rely on the galls for shelter. Tetraponera penzigi, Crematogaster nigriceps, and C. mimosae nest exclusively within swollen thorns, whereas $C$. sjostedti nests within trunk and stem cavities created by wood-boring beetles (Palmer et al. 2008a).

4.3.3 Effect of varied browsing intensities on A. drepanolobium number of spines

There was significant difference in the mean number of spines of trees found in the three levels of browsing. The mean numbers of spines were relatively higher in the most intensively browsed plots- reserve compared to those of the ranch and not browsed (control) plots. (Figure. 11; ANOVA $F=3.784, \mathrm{Df}=2, P$ $=0.023$ ).

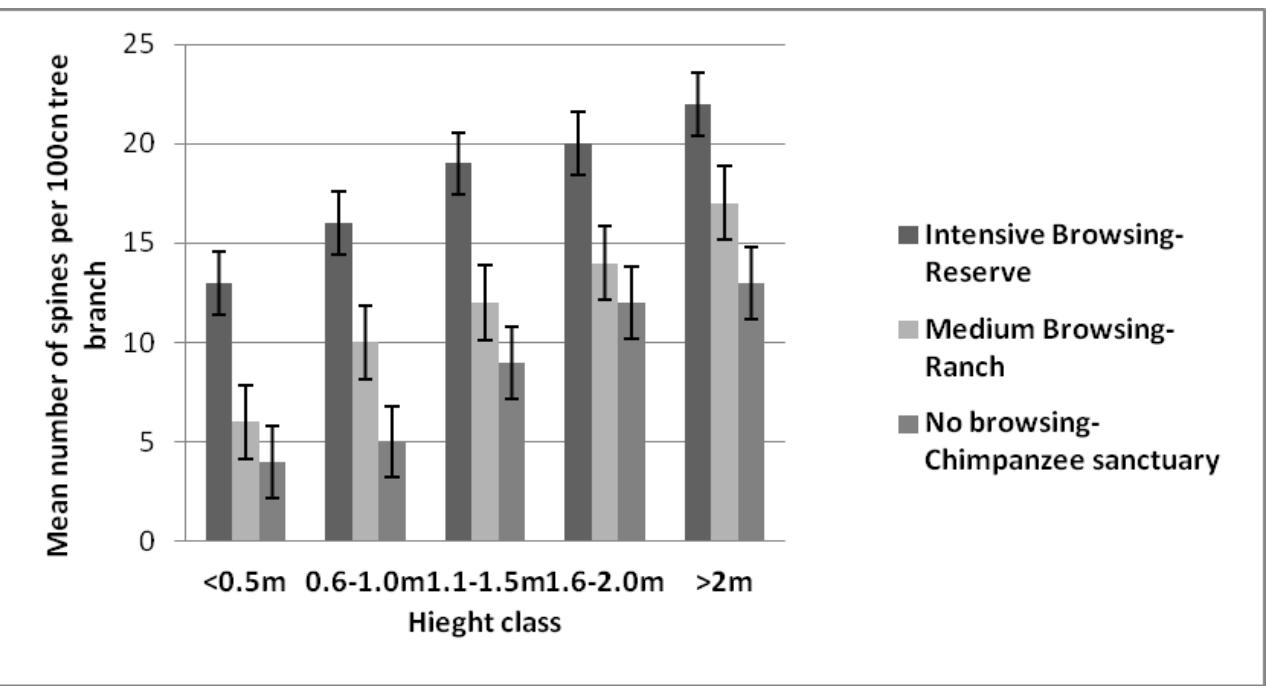


Figure 11: Representation of mean number of spines on $100 \mathrm{~cm}$ branch of Acacia drepanolobium tree in different browsing pressures and tree height classes at Ol Pejeta Conservancy between January 2009 and October 2011 (Error bar = SE). (Source: Researcher, 2020).

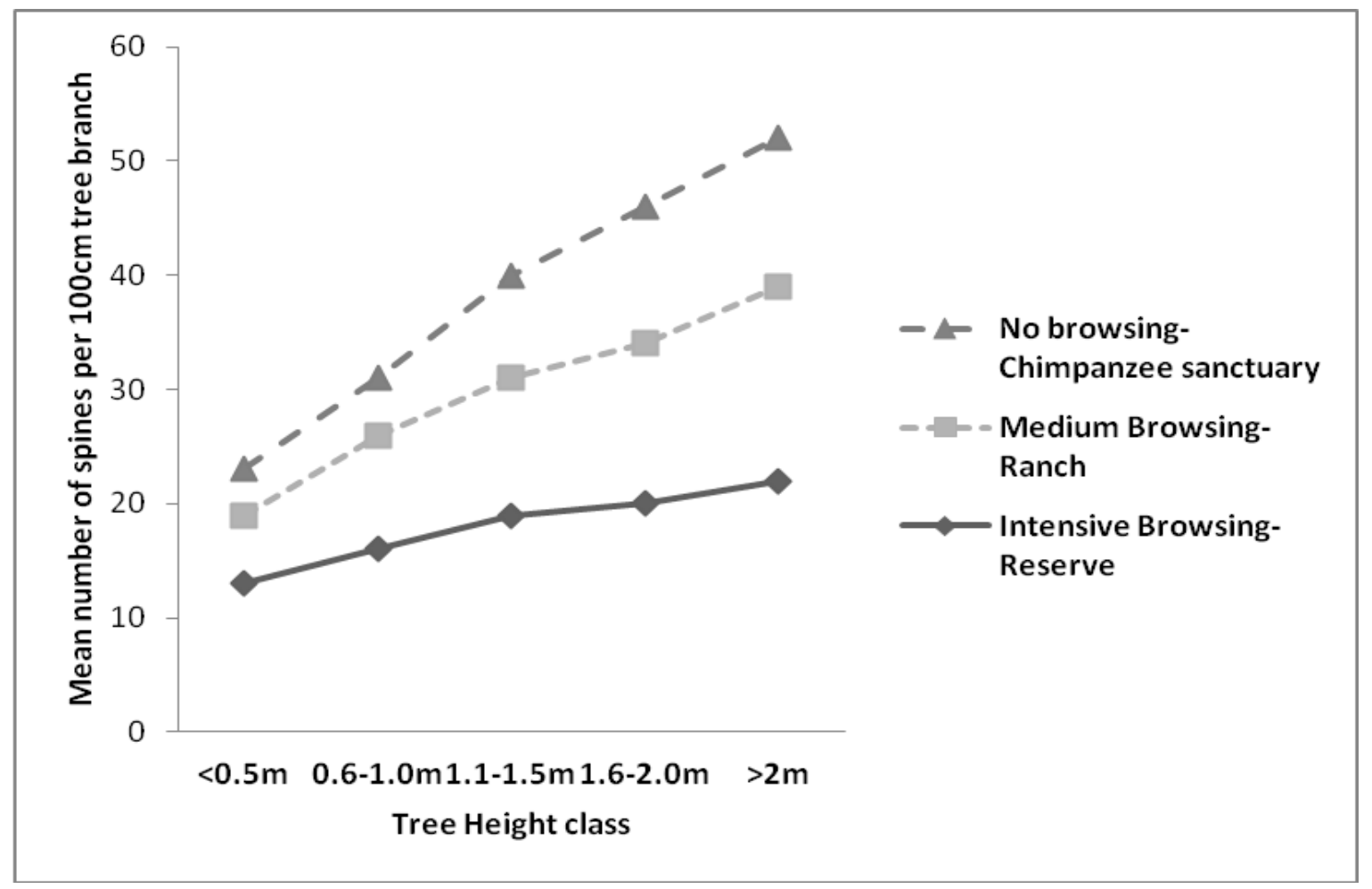

Figure 12: Representation of mean number of spines on $100 \mathrm{~cm}$ branch of Acacia drepanolobium tree in different browsing pressures and tree height classes at O1 Pejeta Conservancy between January 2009 and October 2011. (Source: Researcher, 2020).

Physical protection of $A$. drepanolobium in form of spines was closely compared with specific species of mutualistic ants present on the tree. Ants colonized the trees differently $(\mathrm{t}=20.613, \mathrm{P}<0.05)$ Figure 12. Crematogaster nigriceps colonized trees with the largest number of spines per $100 \mathrm{~cm}$ of branch compared to the other ant species while $C$. sjostedti colonized trees with least number of spines per $100 \mathrm{~cm}$ of branch. The most common resident ant species is Crematogaster mimosae, which occupies 40-60\% of mature trees and appears to be a "true mutualist,"' protecting the tree against herbivores (Young et al. 1997, Palmer et al. 2000). The second most common ant species is $C$. nigriceps, which also defends the tree against herbivores, but prunes most axillary and some terminal shoots, perhaps simulating mammalian herbivory (Young et al. 1997, 2003). Trees inhabited by this ant do not relax thorn length even when protected from mammalian herbivory, Milewski et al. (1999) found out that experimental removal of A. drepanolobium spines caused a threefold increase in mammalian browsing of new leaves. Their results also showed that Length of newly produced spines relaxed by $20 \%$ after two years of complete protection from mammalian browsing and by 35-40\% after five years of protection (Young and Okello 1998, Young et al. 2003). Spines are particularly effective against mammalian herbivores, the primary taxon considered in this study. Other defenses may be used to deter insect herbivores; however, they were beyond the scope of this study. 


\section{Conclusions and Recommendations}

\subsection{Conclusion}

In $\mathrm{Ol}$ pejeta conservancy browsing intensity has statistically significant effect on Crematogaster ants and Acacia drepanolobium interaction; Crematogaster mimosae and $C$. nigriceps were found to be the most ant species occupying trees in the reserve where there is intense browsing and these ant species recruited strongly to disturbances, whereas Tetraponera penzigi mostly inhabited most of the Acacia drepanolobium trees in the ranch where there is intermediate browsing by the herbivores

This study found out that Ant tenancy in A. drepanolobium is influenced by the tree's morphological characteristics; Most aggressive ants' were observed to be occupying trees with high number of galls as a call on need to protect the host tree from intensive browsers. Crematogaster mimosae and C. nigriceps were found to be the most ant species occupying trees with relatively more galls.

1) Crematogaster ant aggression type is associated with number of galls found in $A$. drepanolobium host trees.

2) There is no association between the ant type aggression and the number of spines found in $A$. drepanolobium host trees.

Prescribed burning significantly affected the type of ant inhabiting the Acacia drepanolobium tree. In the burnt plots Crematogaster mimosae occupied most trees followed by Tetraponera penzigi unlike the unburnt plots which recorded high number of trees occupied by Tetraponera penzigi followed by Crematogaster mimosa and $C$. nigriceps respectively.

\subsection{Recommendations}

Acacia drepanolobium trees are important habitat for avifauna and mammals, In Ol pejeta conservancy the woodlands provide food for large herbivores mainly giraffes, endangered black rhinos, elephants, patas monkeys and several other mammals and insects thus proper management of the tree should always be on the check

The results of this research should therefore be used to predict the consequences of heavy browsing pressure, morphological characteristics and prescribed burning on the health of Acacia drepanolobium, an important food item for the endangered black rhinoceros

Mutualisms are key components of biodiversity and ecosystem function, yet the forces maintaining them are poorly understood. Thus, understanding this plant-herbivore relationship given in this research should be used in determining ecological factors that influence conservation sustainability

It is recommended that Managers should therefore often manipulate natural fires or apply prescribed burning to areas where expected increase in productivity may benefit wild or domestic herbivores, particularly grazing ungulates interaction

Studies should be done to determine synergies in Acacia drepanolobium and Crematogaster ants'

\section{Acknowledgements}

I give honor and glory to God for his blessings and precious gift of life throughout the entire study period. My sincere appreciation goes to Egerton University, Faculty of Environment and Resource Development Particularly Natural Resources Department. Gratitude to School of Natural Resources and Environmental Studies, Karatina University College and not forgetting to thank those who took their time to read and positively critique this document. My thanks to the management of Ol pejeta conservancy and Earthwatch International volunteers for their cooperation during the long study period. 


\section{References}

Agrawal, A. A., \& R. Karban. (1997). Domatia mediate plant-arthropod mutualisms. Nature 387:562-563.

Birkett, A. \& Stevens-Wood, B. (2005). Effect of low rainfall and browsing by large herbivores on an enclosed savannah habitat in Kenya. Afr. J. Ecol. 43, 123-130.

Brown W.L. (1960). Ants, acacias and browsing mammals. Ecology 41: 587-592.

Burtt B.D (1942) Some East African vegetation communities. J Ecol 30:65-146

Coe M. J. \& Beentje, H. (1991). A field guide to the acacias of Kenya. Oxford University Press, Oxford.

Davidson, D. W., \& D. M. Mckey (1993). The evolutionary ecology of symbiotic ant- plant relationships. Journal of Hymenoptera Research 2:13-83.

DE moraes, C. M., W. J. Lewis, P. W. Pare', H. T. Alborn, \& J. H. Tumlinson. (1998). Herbivore-infested plants selectively attract parasitoids. Nature 393:570-573.

Dharani, N. (2006). Field Guide to Acacias of East Africa. Stuik Publishers, Cape Town South Africa. 200pp.

Dicke, M., \& J. J. A. Van Loon (2000). Multitrophic effects of herbivore-induced plant volatiles in an evolutionary context. Entomologia Experimentalis et Applicata. 97:237-249.

Dino, M. (2010). Not all ants are equal: Obligate Acacia ants provide different levels of protection against mega herbivores. http;/://www.aginternetwork.net/whalecommonlinelibrary.wiley.com] site visited on 21/3/2020

Frederickson, M. E. (2005). Ant species confer different partner benefits on two neotropical myrmecophytes. Oecologia 143: 387-395.

Fonseca, C. R. (1994). Herbivory and the long-lived leaves of an Amazonian ant-tree. Journal of Ecology 82:833-842.

Fornara, D.A. And Du Toit, J.T. (2007). Browsing lawn? Response of Acacia nigrecens to ungulate browsing in an African savanna.

Beetje, H. J. 1994. Kenya Trees Shrubs and Lianas. National Museum of Kenya, Nairobi. 722pp

Gaume, L, Mckey D. (1999). An ant-plant mutualism and its host-specific parasite: Activity rhythms, young leaf patrolling, and effects on herbivores of two specialist plant-ants inhabiting the same myrmecophyte. Oikos 84:130-44

Gaume, L., M. Zacharias, Grosbois, V..\&. Borges, R. M. (2005). The fitness consequences of bearing domatia and having the right ant partner: experiments with protective and non-protective ants in a semi-myrmecophyte. Oecologia 145:76-86.

Goheen, J. R., \&. Palmer. T. M. (2010). Defensive plant-ants stabilize megaherbivore- driven landscape change in an African savanna. Current Biology 20:1-5.

Heil, M., Fiala, B., Maschwitz, U., Linsenmair K.E. (2001A). On benefits of indirect defence: short- and long-term studies in antiherbivore protection via mutualistic ants. Oecologia 126:395-403.

Hocking, B. (1970). Insect associations with the swollen thorn acacias. Transactions of the Royal Entomological Society of London 122:211-255.

Janzen, D. H. (1967). Interaction of the bull's thorn acacia (Acacia cornigera L.) with an ant inhabitant (Pseudomyrmex ferruginea F.

Smith) in eastern Mexico. University of Kansas Science Bulletin 47:315-558.

Janzen, D.H. (1966). Coevolution of mutualism between ants and acacias. Evolution 20:249-275.

Madden, D. (1988). Examination of thorns and ants as features of defence for East African Acacia. MS Thesis, California State University, Fresno, CA, USA

Madden, D. \& Young T.P. (1992). Symbiotic ants as an alternative defence against giraffe herbivory in spinescent Acacia drepanolobium. Oecologia 91: 235-238.

Milewski, A. V., Young, T. P., \& D. Madden. (1991). Thorns as induced defenses: experimental evidence. Oecologia 86:70-75.

Milewski, A. V., Young, T. P. \& Madden, D (1991). Thorns as induced defenses: experimental evidence. Oecologia 86: 70-75.

Mody, K., \& Linsenmair, K. E. (2004). Plant-attracted ants affect arthropod community structure but not necessarily herbivory. Ecological Entomology 29:217-225.

Monod, T. \& Schmitt, C. (1968) Contribution a l'étude des pseudogalles formicaires chez quelques Acacia africaines. Bull Inst Fond Afrique Noire Ser A 30:903-101

Palmer, T. M. (2003). Spatial habitat heterogeneity influences competition and coexistence in an African acacia ant guild. Ecology $84: 2843-2855$

Palmer, T. M. (2004). Wars of attrition: colony size determines competitive outcomes in a guild of African acacia ants. Animal Behaviour 68:993-1004.

Palmer, T. M., Stanton, T. P., Young, J. R., Goheen, R. M., Pringle, \& Karban, R. (2008A). Breakdown of an ant- plant mutualism follows the loss of large herbivores from an African Savanna. Science 319:192-195.

Palmer, T. M., Young, T. P., Stanton, M. L. \& Wenk, E. (2000). Short-term dynamics of an acacia ant community in Laikipia, Kenya. Oecologia 123:425-435.

Pascoe, J., Morse, D.R., \& Ryan, N.S. (1998). Developing personal technology in the field. Personal Technologies. 2, $28-36$.

Pellew, R. A. (1983). The impact of elephant, giraffe and fire upon the Acacia tortilis woodlands of the Serengeti. African Journal of Ecology 21: 41-78.

Raine, N. E., N. Gammans, I. J. Macfadyen, G. K. Scrivner, \&. Stone, G. N. (2004). Guards and thieves: antagonistic interactions between two ant species coexisting on the same ant-plant. Ecological Entomology 29:345-352.

Stanton, M. L., Palmer, T. M., Young, T. P., Evans, A., \& Turner. M. L. (1999). Sterilization and canopy modification of a swollen thorn acacia tree by a plant-ant. Nature 401:578-581. 
Stapley, L. (1998). The interaction of thorns and symbiotic ants as an effective defence mechanism of swollen-thorn acacias. Oecologia 115:401-405.

Turlings, T. C. J., J. H. Tumlinson, \& Lewis, W. J. (1990). Exploitation of herbivore-induced plant odours by host seeking parasitic wasps. Science 250:1251-1253.

Walter, D. E. (1996). Living on leaves - mites tomenta, and leaf domatia. Annual Review of Entomology 41:101-114

Wahungu, G.M, Mureu, L.K. \& Macharia, P.G (2010) Variability in survival and mortality of Acacia drepanolobium Sjøstedt following prescribed burning at Ol pejeta Conservancy, Kenya. African Journal of Ecology 48; 744-750.

Wahungu, G.M, Kimuyu D.M., Mureu L.K., Birkett, A., Macharia P.G \& Burton, J (2011) Survival, Recruitment and Dynamics of Acacia drepanolobium Sjøstedt seedlings at Ol pejeta Conservancy, Kenya between 1999 and 2009 African Journal of Ecology., 49, 227-233

Wahungu, G.M., Gichohi N. W., Onyango, I, A., Mureu, L. K., Kamaru, D., Mutisya, S., Mulama, M., Kimuyu, D.M. \& Makau, J. (2012). Encroachment of open grasslands and Acacia drepanolobium Harms ex B.Y.Sjöstedt habitats by Euclea divinorum

Hiern in O1 Pejeta Conservancy, Kenya. African Journal of Ecology., 51, 130-138.

Wood, W.F., \& Chong, B., (1975). Alarm pheromones of the East African acacia symbionts: Crematogaster mimosae, and nigriceps. J. Georgia Entomol. Soc. 10, 332-334.

Young, T. P. \& Isbell, L. A. (1991). Sex differences in giraffe feeding ecology: energetic and social constraints. Ethology 87: 79-89.

Young T. P, Stubblefield, C. H, \& Isbell, L. A. (1997). Ants on swollen- thorn acacias: species co-existence in a simple system. Oecologia 109: 98-107.

Young, T.P, \& Smith, A. P. (1987). Herbivory on alpine Mount Kenya. In: Rundel P (ed) Tropical Alpine Systems: Plant Form and Function. Springer, Berlin Heidelberg New York.

Young, T. P. \& Okello, B. D. (1998). Relaxation of an induced defense after exclusion of herbivores: spines on Acacia drepanolobium. Oecologia 115: 508-513.

Young, T. P. And Augustine. D. J. (2007). Intraspecific variation in reproduction response large mammalian herbivores. [http://onlinelibrary.com] site visited on 15/02/2020.

Yu, D.W, Wilson, H.B, \& Pierce, N. E. (2001). An empirical model of species coexistence in a spatially structured environment. Ecology $82: 1761-71$ 